MEXAHIKA

MECHANICS

https://doi.org/10.15407/dopovidi2021.02.029

удК 539.3

\title{
О.Ю. Чирков
}

Інститут проблем міцності ім. Г.С. Писаренка НАН України, Київ

E-mail: chirkale82@gmail.com

\section{Аналіз коректності задач механіки непружного деформування, що враховують вплив напруженого стану на процеси радіаційного розпухання і радіаційної повзучості матеріалу}

\author{
Представлено академіком НАН України В.В. Харченком
}

Розглядаються сучасні моделі радіаційного розпухання і радіаційної повзучості опроміненого матеріалу, в яких враховується пошкоджуюча доза і температура опромінення. Сформульовано визначальні рівняння поведінки матеріалу, що дозволяе описувати неізотермічні процеси непружного деформування з урахуванням радіачійних ефектів змічнення, розпухання і повзучості. Аналіз властивостей визначальних рівнянь дав змогу сформулювати умови, за яких потужність дисипації та потужність, що розвивається додатковими напруженнями на додаткових деформаціях, не зменшуються під час довантаження за умов нейтронного опромінення. На основі одержаних енергетичних нерівностей, що узагальнюють постулат Друкера стосовно опроміненого матеріалу, встановлено умови, які забезпечують коректність рівнянь радіаційної повзучості. Наведено апріорні оцінки гранично допустимої величини пошкоджуючої дози для аустенітної сталі 08X18Н10Т за різних температур опромінення. У практиці розрахунків на міцність одержані оцінки можуть бути корисними на етапі постановки задачі для аналізу адекватності вихідних даних.

Ключові слова: напружений стан, кульовий тензор, девіатор, радіаційне розпухання, радіаційна повзучість.

Обгрунтування міцності, надійності та прогнозування ресурсу елементів внутрішньокорпусних пристроїв (ВКП) ядерних реакторів ВВЕР є одним із вирішальних факторів для визначення можливості та умов довгострокової експлуатації енергоблоків АЕС України. За високих пошкоджуючих доз і температур опромінення аустенітні хромонікелеві сталі типу 08X18Н10T, які використовуються як матеріали ВКП, зазнають радіаційного розпухання і радіаційної повзучості, що може призвести до деградації металу та незворотної формозміни такого елемента ВКП, як вигородка. Збільшення геометричних розмірів конструкції вигородки може вплинути на зміну умов iㅣ охолодження, прискорити процеси розпухання металу та спричинити непроектний тиск вигородки на внутрішньокорпусну шахту

Ци т в в нн я: Чирков О.Ю. Аналіз коректності задач механіки непружного деформування, що враховують вплив напруженого стану на процеси радіаційного розпухання і радіаційної повзучості матеріалу. Допов. Наи. акад. наук Укр. 2021. № 2. С. 29-37. https://doi.org/10/15407/dopovidi2021.02.029 
реактора. Таким чином, для розрахункового обгрунтування міцності та оцінки формозміни вигородки найбільш актуальним є врахування радіаційних ефектів у матеріалі.

Достовірність розрахункового обгрунтування міцності та подовження ресурсу елементів ВКП зумовлена застосуванням у розрахунках напружено-деформованого стану адекватних математичних моделей деформування, в яких враховуються процеси радіаційного розпухання і радіаційної повзучості металу за умов опромінення, високих температур і пошкоджуючої дози.

Зазначимо, що в публікаціях вітчизняних та зарубіжних авторів не досліджена коректність визначальних рівнянь, які дають змогу враховувати вплив напруженого стану на процеси радіаційного розпухання і радіаційної повзучості матеріалу, а також не визначено умови, що забезпечують збіжність наближених методів розв’язання відповідних нелінійних крайових задач. У [1] сформульовано варіант рівнянь теорії пластичності із застосуванням моделі стисненого розпухання і досліджено умови, які забезпечують коректність визначальних рівнянь, однак без урахування радіаційної повзучості матеріалу.

Разом із тим питання, пов’язані з аналізом коректності рівнянь радіаційної повзучості та обгрунтуванням збіжності наближених методів їх розв’язання, досить актуальні. Зазначимо, що досвід розв'язання практичних задач методом скінченних елементів, в яких враховується вплив напружень на радіаційне розпухання і радіаційну повзучість, свідчить про можливе порушення стійкості та збіжності обчислювальних процесів у разі моделювання умов із підвищеними дозою і температурою опромінення.

Зрозуміло, що математична модель, яка описує процес непружного деформування матеріалу в умовах стисненого розпухання від впливу нейтронного опромінення і підвищеної температури, повинна бути сформульована коректно. Використання умов, які забезпечують їі коректність, дає змогу довести однозначну розв’язуваність нелінійної крайової задачі, що відповідає прийнятій моделі непружного деформування, а також обгрунтувати збіжність і точність наближених методів iï розв'язання. Мета даної роботи - аналіз та формулювання умов, які забезпечують коректність розглянутих рівнянь радіаційної повзучості.

Модель радіаційного розпухання. Залежність величини вільного розпухання $R_{0}$ від пошкоджуючої дози $Z$ і температури опромінення $T$ приймається на основі експериментальних досліджень радіаційної пористості опромінених аустенітних сталей [2]:

$$
R_{0}=c_{0} Z^{\beta} \exp \left(-r\left(T-T_{\max }\right)^{2}\right),
$$

де $T_{\max }$ - температура максимального розпухання; $c_{0}, \beta$ та $r-$ константи матеріалу. Рівняння, що описує вплив напружень на розпухання $R$, запропоновано в [2] на основі аналізу експериментальних даних із визначення радіаційного розпухання аустенітних сталей для різних видів напруженого стану. Залежність величини розпухання $R$ від напружень приймається у вигляді

$$
R=R_{0}\left(1+C_{R}\left(\omega \sigma_{m}+(1-\omega) \bar{\sigma}\right)\right)
$$

де $\sigma_{m}-$ середнє нормальне напруження; $\bar{\sigma}-$ інтенсивність напружень; $C_{R}-$ константа матеріалу, яка в загальному випадку залежить від пошкоджуючої дози і температури опромінення; $\omega$ - ваговий множник, який визначає ступінь впливу напружень $\sigma_{m}$ та $\bar{\sigma}$ на 
розпухання $R$. Вибір коефіцієнта $\omega$ здійснюється з урахуванням умови, згідно з якою розпухання $R-$ суть величина додатна. Вважаємо, що можливі значення вагового множника $\omega$ обмежені нерівностями: $0<\omega \leqslant 1$.

Оскільки розпухання $R$ характеризує зміну об’єму, структурні деформації розпухання є компонентами кульового тензора, які залежать як від кульової компоненти, так і від девіаторних компонент тензора напружень. Така концепція зміни об'єму не є загальноприйнятою в рівняннях механіки матеріалів, проте відповідає експериментальним результатам із визначення радіаційного розпухання.

Модель радіаційної повзучості. Для опису сталої швидкості радіаційної повзучості матеріалу використовується рівняння [2]:

$$
\frac{\overline{d \varepsilon^{c}}}{d t}=\left(B_{0} \frac{d Z}{d t}+C_{0} \frac{d R}{d t}\right) \bar{\sigma},
$$

де $\overline{d \varepsilon^{c}}$ - інтенсивність приросту деформації повзучості; $t-$ час або будь-який інший параметр, що характеризує процес навантаження; $B_{0}, C_{0}$ - константи матеріалу, які не суттєво залежать від температури; $d Z / d t$ - швидкість набору пошкоджуючої дози; $d R / d t-$ швидкість розпухання.

Згідно з (1)-(3) швидкість повзучості залежить не тільки від інтенсивності напружень $\bar{\sigma}$, а й від середнього нормального напруження $\sigma_{m}$, тому що розпухання $R$ також залежить від $\sigma_{m}$. Отже, відповідно до прийнятої моделі розпухання девіаторні компоненти деформацій радіаційної повзучості залежать як від девіаторних компонент напружень, так і від кульової компоненти тензора напружень. Така модель повзучості не є загальноприйнятою у класичних теоріях пластичності та повзучості, однак узгоджується з експериментальними даними в разі їх апроксимації рівнянням (3).

Формулювання визначальних рівнянь. Вважаємо, що напружено-деформований стан у точці тіла визначається симетричними тензорами напружень $\sigma=\left(\sigma_{i j}\right)$ і малих деформацій $\sigma=\left(\sigma_{i j}\right) ; \varepsilon=\left(\varepsilon_{i j}\right), 1 \leqslant i, j \leqslant 3$, які можна записати у вигляді двох складових: $\sigma=\sigma_{S}+\sigma_{D}$; $\varepsilon=\varepsilon_{S}+\varepsilon_{D}$, де $\sigma_{S}, \varepsilon_{S}-$ кульові тензори, $\sigma_{D}, \varepsilon_{D}-$ девіатори тензорів напружень і деформацій відповідно.

Завдяки інтегруванню рівнянь пластичної течії та радіаційної повзучості за етап навантаження визначальні рівняння мають наступний вигляд [3]:

$$
\sigma=k_{0}^{R}\left(\varepsilon_{S}-\xi_{S}\right)+2 G_{S}^{R}\left(\varepsilon_{D}+\xi_{D}\right)
$$

де $\xi$ - тензор початкових деформацій,

$$
\xi(t)=\varepsilon_{S}^{T}(t)+\varepsilon_{S}^{R}(t)+\varepsilon_{D}^{p}\left(t^{\prime}\right)+\varepsilon_{D}^{c}\left(t^{\prime}\right),
$$

$\varepsilon_{S}^{T}(t)$ - термічна деформація; $\varepsilon_{S}^{R}(t)$ - структурна об’ємна деформація, яка враховує вплив інтенсивності напружень $\bar{\sigma}(t)$ на розпухання $R(t) ; \varepsilon_{D}^{p}\left(t^{\prime}\right), \varepsilon_{D}^{c}\left(t^{\prime}\right)-$ попередня накопичена пластична деформація і деформація радіаційної повзучості на початок етапу навантаження.

У рівнянні (4) використовуються механічні характеристики опроміненого матеріалу: $k_{0}^{R}$ - модуль всебічного об'ємного розширення з урахуванням поправки на розпухання; 
$G_{s}^{R}-$ січний модуль зсуву матеріалу, що враховує вплив радіаційної повзучості за етап навантаження. Модулі $k_{0}^{R}$ та $G_{s}^{R}$ визначаються для опроміненого матеріалу співвідношеннями [3]:

$$
k_{0}^{R}=\frac{k_{0}}{1+\frac{1}{3} k_{0} R_{0} C_{R} \omega} ; \quad G_{s}^{R}=\frac{G_{s}}{1+3 G_{s}\left(B_{0} \Delta Z+C_{0} \Delta R\right)},
$$

де $k_{0}$ - модуль всебічного об'ємного розширення; $G_{s}-$ січний модуль зсуву опроміненого матеріалу без урахування повзучості; $\Delta Z, \Delta R-$ прирости пошкоджуючої дози $Z$ і розпухання $R$ за етап навантаження.

Рівняння (4)-(6) доповнюються функціональною залежністю деформування опроміненого матеріалу з урахуванням попередньої накопиченої незворотної деформації до початку етапу навантаження $Q\left(t^{\prime}\right)$ та інтенсивності приросту деформації радіаційної повзучості $\overline{\Delta \varepsilon}^{c}$ за етап навантаження [3]:

$$
\bar{\sigma}=\Psi\left(\bar{\varepsilon}^{a}, Q, \overline{\Delta \varepsilon}^{c}, Z, T\right) .
$$

Тоді згідно з (4), (7) вираз для визначення модуля зсуву $G_{s}^{R}$ набуває вигляду:

$$
G_{s}^{R}=\frac{1}{3 \bar{\varepsilon}^{a}} \Psi\left(\bar{\varepsilon}^{a}, Q, \overline{\Delta \varepsilon}^{c}, Z, T\right),
$$

де $\bar{\varepsilon}^{a}$ - інтенсивність девіатора активних деформацій $\varepsilon_{D}^{a}$, які виникають у точці тіла додатково до початкових незворотних деформацій $\varepsilon_{D}^{n}\left(t^{\prime}\right)$,

$$
\varepsilon_{D}^{a}(t)=\varepsilon_{D}(t)-\varepsilon_{D}^{n}\left(t^{\prime}\right), \quad \varepsilon_{D}^{n}\left(t^{\prime}\right)=\varepsilon_{D}^{p}\left(t^{\prime}\right)+\varepsilon_{D}^{c}\left(t^{\prime}\right) .
$$

Зазначимо, що визначальні рівняння (4)-(6), в яких враховуються радіаційне розпухання і радіаційна повзучість опроміненого матеріалу за умов, що викликають напруження, а також конкретизація функціональної залежності (7) для опису зміцнення з урахуванням впливу радіаційної повзучості на криві деформування опроміненого матеріалу більш детально викладено в [3]. Сформульовані рівняння розглядаються, як рівняння радіаційної повзучості, в яких під деформацією повзучості розуміється незворотна деформація, що включає як миттєву пластичну деформацію, так і деформацію радіаційної повзучості.

Аналіз коректності визначальних рівнянь. В основу теоретичного дослідження властивостей визначальних рівнянь радіаційної повзучості покладено наступну концепцію. Коректність визначальних рівнянь (4)-(9) буде тільки в тому разі, якщо не порушуються деякі загальні принципи механіки непружного деформування, що покладені в основу феноменологічних моделей пластичності та повзучості будь-якого виду. Отже, якщо в процесі навантаження елементи середовища зазнають радіаційного розпухання і повзучості внаслідок опромінення, вимагатимемо, щоб потужність дисипації додаткових впливів була невід'ємною:

$$
L=\left(d \sigma, d \varepsilon^{n}\right)=\sum_{1 \leqslant i, j \leqslant 3} d \sigma_{i j} d \varepsilon_{i j}^{n} \geqslant 0 .
$$


По суті, умова (10) є переформулюванням постулату Друкера [4] стосовно матеріалу, що знаходиться під впливом нейтронного опромінення. Підкреслимо, що дане обмеження сформульовано в приростах для повних компонентів напружень і деформацій, на відміну від класичних теорій пластичності та повзучості, в яких це обмеження визначено лише для девіаторних компонент. Ця особливість зумовлена урахуванням у формулі (10) не тільки незворотних деформацій радіаційної повзучості, а й об'ємних деформацій радіаційного розпухання матеріалу.

Отже, вважаємо, що елемент середовища перебуває в деякому початковому стані, який визначається напруженнями $\sigma$. Додамо останнім нескінченно малі прирости $d \sigma$, які призводять до додаткових деформацій $d \varepsilon$. Припускаємо, що зміна напружень відбувається досить повільно, що дає змогу розглядати довантаження елемента для заданої температури і дози опромінення.

Обчислимо спочатку нескінченно малі прирости незворотних деформацій $d \varepsilon_{D}^{n}$ у разі довантаження $d \sigma$. Для цього використаємо співвідношення для скінченних приростів пластичних деформацій $\Delta \varepsilon_{D}^{p}$ і деформацій повзучості $\Delta \varepsilon_{D}^{c}$ за етап навантаження, наведених в [3]:

$$
\Delta \varepsilon_{D}^{p}=\frac{1}{2}\left(\frac{1}{G_{s}}-\frac{1}{G_{0}}\right) \sigma_{D} ; \quad \Delta \varepsilon_{D}^{c}=\frac{3}{2}\left(B_{0} \Delta Z+C_{0} \Delta R\right) \sigma_{D},
$$

звідси з урахуванням другої формули (6) випливає

$$
d \varepsilon_{D}^{n}=\frac{1}{2} d\left(\left(\frac{1}{G_{s}^{R}}-\frac{1}{G_{0}}\right) \sigma_{D}\right)
$$

Тоді згідно з правилами диференціювання складних функцій, маємо

$$
d \varepsilon_{D}^{n}=\frac{1}{2} d\left(\frac{1}{G_{s}^{R}}\right) \sigma_{D}+\frac{1}{2}\left(\frac{1}{G_{s}^{R}}-\frac{1}{G_{0}}\right) d \sigma_{D} .
$$

Окрім того, з урахуванням формул (7) та (8) знаходимо

$$
d\left(\frac{1}{G_{s}^{R}}\right)=\left(\frac{1}{G_{\tau}^{R}}-\frac{1}{G_{s}^{R}}\right) \frac{d \bar{\sigma}}{\bar{\sigma}}
$$

де $G_{\tau}^{R}=1 /\left(3 \Psi^{\prime}\right)$ - дотичний модуль зсуву, що характеризує зміцнення опроміненого матеріалу.

На підставі формул (12)-(14) одержимо

$$
d \varepsilon_{D}^{n}=\frac{1}{2}\left(\frac{1}{G_{\tau}^{R}}-\frac{1}{G_{s}^{R}}\right) \frac{d \bar{\sigma}}{\bar{\sigma}} \sigma_{D}+\frac{1}{2}\left(\frac{1}{G_{s}^{R}}-\frac{1}{G_{0}}\right) d \sigma_{D} .
$$

3’ясуємо умови, за яких потужність дисипації $L$ в процесі довантаження не спадає. Для цього використовуємо розкладання

$$
d \varepsilon^{n}=d \varepsilon_{S}^{n}+d \varepsilon_{D}^{n},
$$


де деформації $d \varepsilon_{D}^{n}$ обчислюються за допомогою формули (15), а кульова складова незворотних деформацій $d \varepsilon_{S}^{n}$ характеризує незворотну зміну об'єму внаслідок розпухання $R$ і тому визначається виразом

$$
\varepsilon_{S}^{n}=\frac{1}{3} R \boldsymbol{s}_{1},
$$

де $\boldsymbol{s}_{1}-$ одиничний кульовий тензор, його модуль дорівнює $\sqrt{3}$.

Отже, з урахуванням співвідношень (1), (2), (17) маємо

$$
d \varepsilon_{S}^{n}=\frac{1}{3} R_{0} C_{R}\left(\omega d \sigma_{m}+(1-\omega) d \bar{\sigma}\right) \boldsymbol{s}_{1}
$$

На підставі (10) та (15)-(18) знаходимо

$$
L=\left(d \sigma, d \varepsilon^{n}\right)=L_{11}\left(d \sigma_{m}\right)^{2}+2 L_{12} d \sigma_{m} \overline{d \sigma}+L_{22}(\overline{d \sigma})^{2}
$$

де коефіцієнти квадратичної форми (19) визначаються наступним чином:

$$
\begin{aligned}
& L_{11}=R_{0} C_{R} \omega>0 ; \quad L_{12}=\frac{1}{2} R_{0} C_{R}(1-\omega) d \sigma_{m} \overline{d \sigma} \cos \psi ; \\
& L_{22}=\frac{1}{3}\left(\left(\frac{1}{G_{s}^{R}}-\frac{1}{G_{0}}\right) \sin ^{2} \psi+\left(\frac{1}{G_{\tau}^{R}}-\frac{1}{G_{0}}\right) \cos ^{2} \psi\right)>0 .
\end{aligned}
$$

У формулах (19) та (20) враховано, що

$$
\left(d \sigma_{S}, \boldsymbol{s}_{1}\right)=3 d \sigma_{m} ; \quad \bar{\sigma}=\sqrt{\frac{3}{2}\left(\sigma_{D}, \sigma_{D}\right)} ; d \bar{\sigma}=\frac{3}{2 \bar{\sigma}}\left(\sigma_{D}, d \sigma_{D}\right) ;
$$

ч - кут довантаження, який визначається співвідношеннями:

$$
d \bar{\sigma}=\overline{d \sigma} \cos \psi ; \overline{d \sigma}=\sqrt{\frac{3}{2}\left(d \sigma_{D}, d \sigma_{D}\right)} .
$$

Якщо квадратична форма (19) матиме властивість додатної напіввизначеності, одержимо необхідну і достатню умову для виконання нерівності $L \geqslant 0: L_{11} L_{22}-L_{12}^{2} \geqslant 0$, звідки маємо

$$
4 \omega\left(\frac{1}{G_{\tau}^{R}}-\frac{1}{G_{0}}\right) \geqslant 3 R_{0} C_{R}(1-\omega)^{2} .
$$

3’ясуємо тепер умови виконання нерівності, що випливає з постулату Друкера та полягає в тому, що потужність, яка розвивається додатковими напруженнями на додаткових деформаціях повинна бути додатною:

$$
A=(d \sigma, d \varepsilon)>0 .
$$

Для цього використаємо розкладання приросту повних деформацій $d \varepsilon$ у такому вигляді: 


$$
d \varepsilon=d \varepsilon^{e}+d \varepsilon^{n}
$$

де деформації $d \varepsilon^{n}$ обчислюється за допомогою формул (15)-(18), а пружна складова $d \varepsilon^{e}$ визначаються узагальненим законом Гука:

$$
d \varepsilon^{e}=\frac{1}{k_{0}} d \sigma_{S}+\frac{1}{2 G_{0}} d \sigma_{D}
$$

Отже, на підставі (6), (15)—(18), (25) та (26) маємо

$$
d \varepsilon=\frac{1}{k_{0}^{R}} d \sigma_{S}+\frac{1}{3} R_{0} C_{R}(1-\omega) d \bar{\sigma} \boldsymbol{s}_{1}+\frac{1}{2}\left(\frac{1}{G_{\tau}^{R}}-\frac{1}{G_{s}^{R}}\right) \frac{d \bar{\sigma}}{\bar{\sigma}} \sigma_{D}+\frac{1}{2 G_{s}^{R}} d \sigma_{D}
$$

Якщо підставити у формулу (24) вираз для приростів деформацій (27), то одержимо

$$
A=(d \sigma, d \varepsilon)=A_{11}\left(d \sigma_{m}\right)^{2}+2 A_{12} d \sigma_{m} \overline{d \sigma}+A_{22}(\overline{d \sigma})^{2}
$$

де коефіцієнти квадратичної форми (28) визначаються так:

$$
\begin{aligned}
& A_{11}=\frac{3}{k_{0}^{R}}>0 ; \quad A_{12}=\frac{1}{2} R_{0} C_{R}(1-\omega) \cos \psi \\
& A_{22}=\frac{1}{3}\left(\frac{1}{G_{s}^{R}} \sin ^{2} \psi+\frac{1}{G_{\tau}^{R}} \cos ^{2} \psi\right)>0 .
\end{aligned}
$$

Квадратична форма (28) подана стосовно змінних $d \sigma_{m}, \overline{d \sigma}$ і тому умова їі додатної визначеності полягає у виконанні нерівності: $A_{11} A_{22}-A_{12}^{2}>0$. Таким чином, одержуємо необхідну і достатню умову, яка забезпечує нерівність $A>0$ :

$$
4>k_{0}^{R} G_{\tau}^{R}\left(R_{0} C_{R}(1-\omega)\right)^{2} .
$$

Для виконання умови (30) потрібні менш жорсткі обмеження на вихідні дані порівняно з нерівністю (23). Дійсно, з нерівності (23) випливає оцінка

$$
4>\frac{3}{\omega} G_{\tau}^{R} R_{0} C_{R}(1-\omega)^{2},
$$

звідси з урахуванням рівності

$$
k_{0}^{R} R_{0} C_{R}=\frac{3}{\omega}\left(1-\frac{k_{0}^{R}}{k_{0}}\right)
$$

приходимо до умови (30). Отже, якщо справедлива нерівність (23), то умова (30) тим більше справедлива.

Оцінимо гранично допустиму дозу опромінення $Z_{\max }$, перевищення якої може призводити до порушення коректності рівнянь (4). Для цього використаємо умову (30), в якій 
покладемо $G_{\tau}^{R}=G_{0}^{R}$, що відповідає модулю зсуву на пружній ділянці кривої деформування опроміненого матеріалу. Такий вибір цілком прийнятний, оскільки виконання умови (30) необхідне для всіх можливих значень $G_{\tau} \leqslant G_{0}^{R}$, а вибір $G_{\tau}^{R}=G_{0}^{R}$ зумовлює найбільш консервативну оцінку дози $Z_{\max }$.

Нижче наведені апріорні оцінки граничних значень $Z_{\max }$ для аустенітної сталі марки 08X18Н10T залежно від температури опромінення. Розрахунки проводили з використанням медіанної залежності вільного розпухання і коефіцієнтів рівнянь, що описують радіаційне розпухання і повзучість аустенітних сталей [2]. Результати одержані для відношень $R / R=0,5 ; 0,75 ; 1$ та приростів доз $\Delta Z=0,1 ; 0,5$ у зсувах на атом (зна)

Оцінимо $Z_{\max }$ за таких умов: температура опромінення $T=400{ }^{\circ} \mathrm{C}$; модуль Юнга $E=1,78 \cdot 10^{5}$ МПа; коефіцієнт Пуассона $v=0,31$. У разі $\Delta Z=0,1$ зна знаходимо $Z_{\max }=63,3$; 64,$7 ; 66,1$ зна, для умови $\Delta Z=0,5$ зна маємо $Z_{\max }=76,7 ; 84,4 ; 92,5$ зна, неврахування повзучості дає $Z_{\max }=60,1$ зна.

Більш консервативна оцінка пошкоджуючої дози $Z_{\max }$ відповідає температурі максимального розпухання $T_{\max }=470^{\circ} \mathrm{C}$. Оскільки для такої температури $E=1,73 \cdot 10^{5} \mathrm{MПа} \mathrm{і}$ $v=0,31$, для $\Delta Z=0,1$ зна знаходимо $Z_{\max }=40,9 ; 42,3 ; 43,7$ зна, для умови $\Delta Z=0,5$ зна маємо $Z_{\max }=53,8 ; 62,2 ; 71,2$ зна, оцінка без урахування повзучості дає $Z_{\max }=37,9$ зна.

Наведемо ще оцінки $Z_{\max }$ для температури опромінення, що вища $T_{\max }$. Якщо $T=530{ }^{\circ} \mathrm{C}$, маємо $E=1,68 \cdot 10^{5}$ МПа і $v=0,32$, звідси для умови $\Delta Z=0,1$ зна знаходимо $Z_{\max }=57,9$; 59,$3 ; 60,7$ зна, у разі $\Delta Z=0,5$ зна одержуємо $Z_{\max }=71,1 ; 78,8 ; 87,2$ зна, без врахування повзучості $Z_{\max }=54,9$ зна.

Згідно з одержаними оцінками збільшення протяжності етапів навантаження призводить до менш консервативних оцінок пошкоджуючої дози опромінення. Апріорні оцінки мають наближений характер, проте в практиці розрахунків на міцність вони можуть бути корисними на етапі постановки задачі для визначення етапів навантаження і аналізу адекватності вихідних даних.

Отже, основний результат аналізу задач механіки непружного деформування, в яких враховується вплив напруженого стану на процеси радіаційного розпухання і радіаційної повзучості матеріалу, полягає в наступному. У разі виконання умови (30) існує взаємнооднозначна відповідність між напруженнями і деформаціями у вигляді визначальних рівнянь (4). На основі одержаних енергетичних нерівностей, що узагальнюють постулат Друкера стосовно опроміненого матеріалу, встановлено умови, які забезпечують коректність сформульованих рівнянь радіаційно повзучості.

\section{ЦИТОВАНА ЛІТЕРАТУРА}

1. Чирков А.Ю. О корректности известной математической модели радиационного распухания, учитывающей влияние напряжений, в задачах механики упругопластического деформирования. Пробл. прочности. 2020. № 2. С. 5-22.

2. Марголин Б.З., Мурашова А.И., Неустроев В.С. Анализ влияния вида напряженного состояния на радиационное распухание и радиационную ползучесть аустенитных сталей. Пробл. прочности. 2012. № 3. C. $5-24$. 
3. Чирков О.Ю. Аналіз коректності відомої моделі радіаційної повзучості, що враховує вплив напружень, у задачах механіки непружного деформування. Повідомлення 1. Формулювання визначальних рівнянь. Пробл. міиності. 2021. № 2. С. 5-20.

4. Качанов Л.М. Основы теории пластичности. Москва: Наука, 1969. 420 с.

Надійшло до редакції 02.03.2021

\section{REFERENCES}

1. Chirkov, A.Yu. (2020). On the Correctness of the Well-Known Mathematical Model of Irradiation-Induced Swelling with the Influence of Stresses in the Problems of Elastic-Plastic Deformation Mechanics, Strength of Materials, 52, No. 2, pp. 183-198.

2. Margolin, B., Murashova, A. \& Neustroiev, V. (2012). Analysis of the Influence of Type Stress State on Radiation Swelling and Radiation Creep of Austenitic Steels, Strength of Materials, 44, No. 3, pp. 227-240.

3. Chirkov, O.Yu. (2021). Analysis of the Correctness of the Well-Known Model of Radiation Creep with the Influence of Stresses in the Problems of Mechanics of Inelastic Deformation. Part 1. Formulation of Defining Equations, Strength of Materials (in press).

4. Kachanov, L.M. (1969). Fundamentals of the Theory of Plasticity. Moscow: Nauka (in Russian).

Received 02.03.2021

\section{O. Yu. Chirkov}

Pisarenko Institute of Problems of Strength of the NAS of Ukraine, Kyiv

E-mail: chirkale82@gmail.com

\section{ANALYSIS OF THE CORRECTNESS OF PROBLEMS IN THE MECHANICS OF INELASTIC DEFORMATION WITH THE INFLUENCE OF A STRESSED STATE ON THE PROCESSES OF RADIATION SWELLING AND RADIATION CREEP OF THE MATERIAL}

Modern models of radiation swelling and radiation creep of irradiated materials are considered, taking the damaging dose and irradiation temperature into account. The constitutive equations are formulated that allow describing the non-isothermal processes of inelastic deformation of the material with regard for the radiation effects of hardening, swelling, and creep. Analysis of properties of the constitutive equations made it possible to formulate conditions under which the power of dissipation and the power developed by additional stresses on additional deformations do not decrease under neutron irradiation loading conditions. On the basis of the obtained energy inequalities, which generalize Drucker's postulate in relation to the irradiated material, conditions are established that ensure the correctness of the radiation creep equations. A priori estimates of the maximally permissible value of the damaging dose for austenitic steel for various irradiation temperatures are given. In the practice of strength calculations, the obtained estimates can be useful at the stage of setting the problem for analyzing the adequacy of the initial data.

Keywords: stressed state, spherical tensor, deviator, radiation swelling, radiation creep. 